\title{
Dos islas, una frontera, un mestizaje: Una metáfora sobre la comunicación y el cuidado
}

\author{
Two islands, one border, one mestizaje: \\ A metaphor for communication and care
}

\author{
Duas ilhas, border, mestiçagem: \\ Uma metáfora para a comunicação e cuidado \\ Juan Carlos Delgado Antolín
}

Enfermero, Antropólogo. Enfermero de Atención Primaria C. S. de Griñón, Madrid. Profesor externo de la Universidad Rey Juan Carlos, Madrid

Cómo citar este artículo en edición digital: Delgado Antolín, J.C. (2015). Dos islas, una frontera, un mestizaje: Una metáfora sobre la comunicación y el cuidado. Cultura de los Cuidados (Edición digital), 19(43). Disponible en: $<$ http://dx.doi. org/10.14198/cuid.2015.43.05>

Correspondencia: C/ Villamanín $318^{\circ} \mathrm{F} 28011$ Madrid.

Correo electronico: jcdantolin@gmail.com

Recibido: 09/06/2015; Aceptado: 12/09/2015

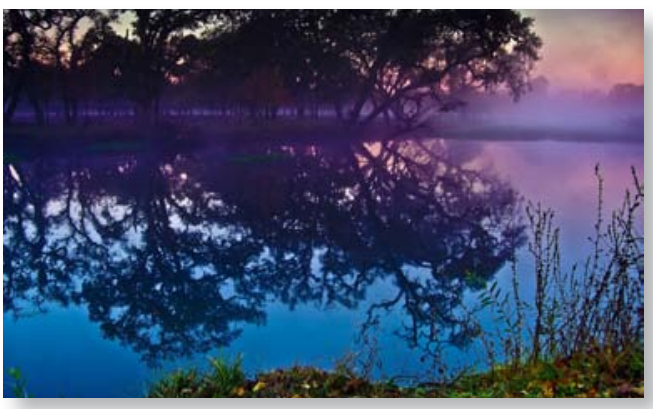

ABSTRACT

It is an opinion, a personal reflection metaphorically, on the evolution of the nursing process, based on the System Caregiver Ratio Dorothea Orem. As a care process from the initial ratio of distance, approaching two personalities can go two evaluative own visions and converge on a common vision and hybridized with a single purpose, caring for the person. The tool to use is communication.

Keywords: care, communication, health relationship, values.

\section{RESUMO}

É uma opinião, uma reflexão pessoal metaforicamente, sobre a evolução do processo de enfermagem, com base na Relação Sistema Cuidador de Dorothea Orem. Como um processo de cuidado a partir da relação inicial de distância, aproximando-se duas personalidades podem ir duas próprias visões de avaliação e convergem para uma visão híbrida comum e um objetivo, cuidar da pessoa. A ferramenta a ser usada é a comunicação.

Palavras-chave: Cuidado, Comunicação, relacionamento saúde, valores.

\section{RESUMEN}

Es un artículo de opinión, una reflexión personal en forma metafórica, sobre la evolución del proceso de enfermería, basándome en los Sistema de Relación Cuidadora de Dorothea Orem. Como en un proceso de cuidado desde la relación inicial de lejanía, pueden irse acercándose dos personalidades, dos visiones valorativas propias y confluir en una visión común híbrida y con un único fin, el cuidado de la persona. La herramienta a emplear es la comunicación.

Palabras claves: Cuidado, comunicación, relación sanitaria, valores. 
Cuando hablamos del cuidado profesional casi siempre lo hacemos de un modo conceptual, intentando explicar sus características, sus conceptos básicos de desarrollo, la historia de sus orígenes, su situación actual, la influencia del componente femenino en su ejercicio, etc., es decir, hablamos del cuidado desde un punto de vista teórico y explicativo de su realidad o de una parcela de su realidad. Pero el cuidado de los seres humanos, todo tipo de cuidado y especialmente el cuidado profesional, siempre se da dentro de una relación, una relación interpersonal y donde como poco deben existir dos personas, un dador y un receptor de cuidados. Normalmente, los profesionales de enfermería son los encargados de proporcionar y establecer esos cuidados y las personas con necesidades alteradas, reales o potenciales, los reciben. Bien, pues partiendo de este hecho aparentemente simple, se puede establecer toda una relación que a medida que crece, se complica y se va haciendo más compleja. La maestra Dorothea Orem hablaba (Donobue Eben, Nation, Marriner, y Nordermeyer, 1989: 104) de tres sistemas en la relación cuidadora: Sistemas de Enfermería totalmente compensatorios, la enfermera debe compensar la incapacidad total de los pacientes para el autocuidado. Sistemas parcialmente compensatorios, la enfermera compensa ciertos déficit en el autocuidado. Sistemas de apoyo-educativo, la enfermera enseña y fomenta el autocuidado en el paciente. El objetivo de la Enfermería es avanzar en estos sistemas lo más posible y si las circunstancias nos lo permiten, debemos llegar al último sistema en la relación cuidadora, es decir, al sistema que proporciona la mayor autonomía e independencia a la persona cuidada, mediante el empoderamiento y la autosuficiencia, pues el objetivo fundamental es proporcionar el máximo sistema de autocuidado y autogobierno a la persona, que ha pasado por un proceso de necesidades alteradas y que la ha incapacitado para su pleno desarrollo.

El título de esta reflexión "Dos islas, una frontera, un mestizaje: Una metáfora sobre la comunicación y el cuidado" es fruto de lo que pretende ser una evolución desde una relación totalmente dependiente hasta una relación de apoyo-educativo, donde se pretende y se quiere potenciar un horizonte de máxima independencia.

En los Sistemas totalmente compensatorios, al principio se establecerá una relación entre dos personas ajenas. Tan sólo les une una relación profesional de incapacidad y de complejidad en la labor cuidadora, me explicaré: Una persona que hasta ese momento era capaz de ejercer el autocuidado y este se encontraba instaurado dentro de su vida común, de su cotidianeidad, se encuentra incapaz de seguir autocuidándose, pues el hecho normal $y$ cotidiano, se ha convertido en un hecho excepcional y complejo que necesita de la acción y de la ejecución de una persona experta, de una enfermera. Esta necesidad alterada pone en contacto a dos personas, dos islas, que sintiéndose próximas están separadas. Cada una maneja y conoce una corporeidad propia y diferente de la otra, una al ser profesional, ha podido explorar más en otras corporeidades, en otros comportamientos, en otras necesidades, pero la persona a cuidar es una isla, incluso una isla virgen a esta nueva etapa de la dependencia. Cada una conoce su terreno, pero todavía no comparten nada en común. La relación comienza y los objetivos parecen comunes, de hecho deben ser comunes, el bien de la persona cuidada. En un principio cada una tiene unas ideas de cómo debe ser la relación y unos valores en los que debe moverse y llevar 
a cabo esa relación. Pronto empiezan a comunicarse, hay puentes de unión, trasportes de intercambios. El acercamiento entre las dos islas es progresivo y se puede decir que con el tiempo, llegan casi a unirse. Si han fijado y delimitado bien la finalidad de la relación, el cuidado de la persona con las necesidades alteradas, y se han ido limando las continuas asperezas que surgen en toda relación, un sentimiento de acercamiento y de proximidad se puede poner de manifiesto en la relación cuidadora. Pero dos personas, dos islas no pueden unirse en una sola, siempre se conservan rasgos de identidad propios, pues existen fronteras.

Con el tiempo y la comunicación las personas pueden conocerse, reunirse y transformar esas dos islas en las que comenzaron su relación en un archipiélago, pero la línea de separación será una frontera. Esas líneas imaginarias es lo que tienen, que separan, ponen límites. Al fin y al cabo son dos personas, dos identidades propias que conviven y en este caso poseen una finalidad común. Pero a las vez las fronteras lo mismo que sirven para separar, son puntos de unión, de aproximación. Todos los terrenos fronterizos nos hablan de la proximidad del otro. Otro diferente a mí, pero próximo, vecino y por lo tanto cercano. Con el que me tengo que entender, con el que tengo que llegar a acuerdos y cuando este en su lado de la frontera, nuestra relación se regirá por las normas de su lado, pero cuando estemos en mi lado, las normas serán las mías. Las fronteras por tanto separan y aproximan, pues muchas veces, cuando pasamos una frontera estamos donde realmente queríamos ir.

Así cuando pasamos de un Sistema totalmente compensatorio a un Sistema parcialmente compensatorio, estamos en un terreno completamente fronterizo, pues somos dos en

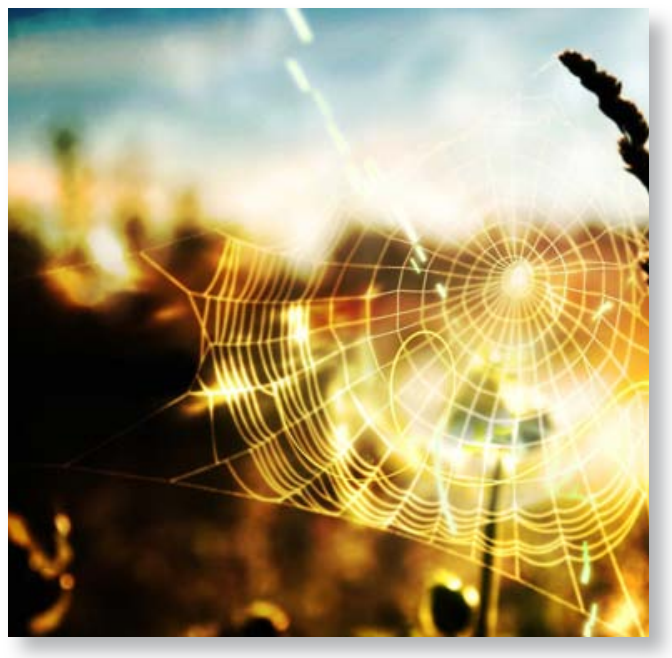

uno. Nos situamos a ambos lados de la frontera según la necesidad a tratar, según la actividad a desarrollar en el cuidado. Cuando se va compensando el sistema, el desarrollo del cuidado y la actividad lo realizará, según la complejidad y la destreza, una parte u otra de la frontera. Parte del cuidado será autocuidado y parte del cuidado seguirá siendo "heterocuidado", es decir, dependiente de otra persona. El cuidado seguirá avanzando hacia la independencia, pero en un terreno aún incierto. La aproximación de las islas se ha producido, pero cada una tiene su competencia claramente definida.

Por último, llegamos al último Sistema al apoyo-ayuda. Las islas son independientes, fronterizas y ahora llega el momento de crear una cultura mestiza, al fin y al cabo cada vez parece más seguro que el homo sapiens moderno es un mestizaje del ADN de varias especies (homo sapiens, homo neanderthalensis, denisovanos y posiblemente homo erectus) (Meyer, et al., 2014; Nieves, 2013). Una cultura mestiza en ese terreno incierto donde nos encontramos, donde las normas de unos y de otros sean respetadas. Donde desde el diálogo y la escucha activa mantenida, se lleguen a acuerdos. En el sistema de apoyo se establece 
un mestizaje donde los cuidados ya proporcionados por el propio paciente son asesorados y potenciados por la enfermera, pero con los valores del paciente y la matización de los valores del profesional como experto en la materia que se trata. La hibridación producida entre los valores de uno y otro, nos llevará a obtener el respeto por parte de ambos. Sólo en el mestizaje se llega a una plena integración de la interculturalidad. Sólo las personas mestizas son interculturales y eligen en cada momento lo mejor de las dos culturas y las potencian de una manera integrada, participando de lo mejor de cada una en cada momento, en cada lugar y en cada circunstancia. Pues se han desprendido de los prejuicios de cada lado para establecer un nuevo estatus criollo de integración.

La interculturalidad es el paso previo a la transculturalidad, como un orden totalmente independiente de las creencias culturales sesgadas y separadoras entre las personas. Cuando uno se siente intercultural y comienza a entender que su modo de ser, de pensar, de obrar, puede ser bueno para él, pero no tiene que ser el mejor para otro, y capta la capacidad de mejora que tienen otras ideas y otras culturas y que esas ideas y valores le pueden servir también a él, estamos entrando en la interculturalidad. En la interculturalidad los valores, las ideas, los hechos culturales se funden y se va creando poco a poco un híbrido, un mestizo con aportaciones de uno y otro lado. Sólo en ese momento se está comenzando a avanzar hacia el cuidado transcultural y se es capaz de ser un cuidador sin islas, sin fronteras y con un claro sentido de mezcla. Habrá superado la isla como separación, la frontera como proximidad y el mestizaje como integración.

Por supuesto, que este viaje virtual a través de la insularidad se puede dar en los tres

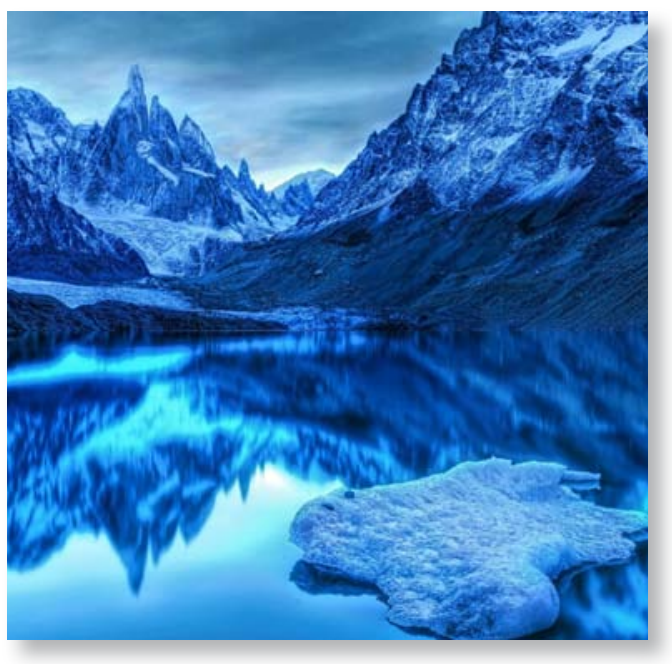

sistemas y que a veces, en cada uno de ellos no pasamos de ser islas y de evitar la aproximación por si acaso, por el qué dirán o por si las moscas. Aunque en las etapas iniciales de un sistema totalmente compensatorio no se pueda ejercer ciertas cotas de autocuidado, se puede llegar a ejercer un cuidado individual con el conocimiento y el mestizaje de los valores integrados entre el profesional y la persona cuidada. Es decir, que el "islamiento", las fronteras y el mestizaje dependerán más de nosotros, de ambos, que de la situación física y de dependencia que se dé en la realidad.

Si en el mundo de los valores y su influencia a la hora de ejercer el cuidado debemos avanzar hacia la interculturalidad y hacia una cierta transculturalidad, en toda relación humana también se puede profundizar y que llegue a tener un efecto y un componente transpersonal.

La relación transpersonal, la podríamos definir como una relación que traspasa el plano netamente personal y va más allá, estableciéndose una relación mayor, más significativa y con un mayor compromiso. Es una relación que se da entre personas y que muchas veces su producto transciende la pura relación comunicativa para producir un efecto complejo 
y completo, donde se ponen de manifiesto una relación que abarca todos los planos entre las personas que intervienen en la relación. Ese nivel implica una conexión donde los deseos y las necesidades alteradas de una de las partes, son percibidas de una forma especial por la otra parte, la que proporciona los cuidados, transcendiendo su conexión el plano de la comunicación hablada o gestual.

La comunicación sigue siendo una de las herramientas más eficaces que poseemos las enfermeras, y la comunicación no se compone sólo de lenguaje verbal, también la compone el lenguaje no verbal y el contacto, y por supuesto debe ser seguida de una buena y autentica deliberación por ambas partes. Estamos acostumbrados a defender nuestras ideas como las auténticas, como las verdaderas, como las más valiosas y hablamos pero no escuchamos, decimos pero no oímos y a lo mejor los otros tienen razón, pues sus circunstancias, sus ámbitos y sus contextos son diferentes a los míos y por tanto para ellos sus ideas son más valiosas.
Debemos hacer un ejercicio de humildad e intentar pensar que a lo mejor yo estoy equivocado y ellos pueden tener razón. Aunque sea por un solo instante. Luego podemos volver a nuestra auténtica y valiosa verdad.

Fin de la metáfora.

\section{BIBLIOGRAFÍA}

- Donobue Eben, J., Nation, M. J., Marriner, A., Nordermeyer, S. B., (1989). Dorotehea E. Orem: Teoría del déficit de auto-cuidado en Enfermería. En A. Marriner (Eds), Modelos y teorías de Enfermería. Barcelona: Ediciones Rol.

- Meyer, M., Fu, Q., Aximu-Petri, A., Glocke, I., Nickel, B., Arsuaga, J.L., Martínez,... y E., Pääbo, S. (2014). Amitochondrial genome sequence of a hominin from Sima de los Huesos. Nature, 505 (7483), 403-406.

- Nieves, J. M. (2013). Los humanos éramos cuatro especies que se apareamos entre sí. El Blog ciencia y tecnología ABC, Madrid (18-12-2013). Recuperado de http:// abcblogs.abc.es/nieves/public/post/los-humanos-eramos-cuatro-especies-que-se-aparearon-entre-si-16196. asp/ 